Original article

\title{
Chemokine CCL5/RANTES inhibition reduces myocardial reperfusion injury in atherosclerotic mice
}

\author{
Vincent Braunersreuther ${ }^{\mathrm{a}}$, Corinne Pellieux ${ }^{\mathrm{a}}$, Graziano Pelli ${ }^{\mathrm{a}}$, Fabienne Burger ${ }^{\mathrm{a}}$, Sabine Steffens ${ }^{\mathrm{a}}$, \\ Christophe Montessuit ${ }^{\mathrm{a}}$, Christian Weber ${ }^{\mathrm{d}}$, Amanda Proudfoot ${ }^{\mathrm{e}}$, François Mach ${ }^{\mathrm{a}, *, 1}$, Claire Arnaud ${ }^{\mathrm{a}, \mathrm{b}, \mathrm{c}, 1}$ \\ a Division of Cardiology, Department of Medicine, University Hospital, Foundation for Medical Researches, 64 Avenue Roseraie, 1211 Geneva, Switzerland \\ b INSERM ERI17, Grenoble, F-38042, France \\ ' Université Joseph Fourier, Faculté de Médecine, IFR1, Grenoble, F-38402, France \\ d Cardiovascular Molecular Biology Institute Aachen, 52074 Aachen, Germany \\ e Merck Serono Geneva Research Centre, 1202 Geneva, Switzerland
}

\section{A R T I C L E I N F O}

\section{Article history:}

Received 24 July 2009

Accepted 29 July 2009

Available online 7 August 2009

\section{Keywords:}

Myocardial ischemia

Reperfusion injury

Inflammation

Chemokines

CCL5/RANTES

\begin{abstract}
A B S T R A C T
Although beneficial for cardiomyocyte salvage and to limit myocardial damage and cardiac dysfunction, restoration of blood flow after prolonged ischemia exacerbates myocardial injuries. Several deleterious processes that contribute to cardiomyocyte death have been proposed, including massive release of reactive oxygen species, calcium overload and hypercontracture development or leukocyte infiltration within the damaged myocardium. Chemokines are known to enhance leukocyte diapedesis at inflammatory sites. The aim of the present study was to investigate the effect of chemokine CCL5/RANTES antagonism in an in vivo mouse model of ischemia and reperfusion. $\mathrm{ApoE}^{-/-}$mice were submitted to $30 \mathrm{~min}$ ischemia, by ligature of the left coronary artery, followed by $24 \mathrm{~h}$ reperfusion. Intraperitoneal injection of $10 \mu \mathrm{g}$ of CCL5/RANTES antagonist $\left[{ }^{44} \mathrm{AANA}{ }^{47}\right]$-RANTES, 5 min prior to reperfusion, reduced infarct size as well as Troponin I serum levels compared to PBS-treated mice. This beneficial effect of $\left[{ }^{44} \mathrm{AANA}{ }^{47}\right]$-RANTES treatment was associated with reduced leukocyte infiltration into the reperfused myocardium, as well as decreased chemokines Ccl2/ Mcp-1 and Ccl3/Mip-1 $\alpha$ expression, oxidative stress, and apoptosis. However, mice deficient for the CCL5/ RANTES receptor Ccr5 did not exhibit myocardium salvage in our model of ischemia-reperfusion. Furthermore, $\left[{ }^{44} \mathrm{AANA}^{47}\right]$-RANTES did not mediate cardioprotection in these $\mathrm{ApoE} \mathrm{E}^{-/-} \mathrm{Ccr}^{-/-}$deficient mice, probably due to enhanced expression of compensatory chemokines. This study provides the first evidence that inhibition of CCL5/RANTES exerts cardioprotective effects during early myocardial reperfusion, through its anti-inflammatory properties. Our findings indicate that blocking chemokine receptor/ligand interactions might become a novel therapeutic strategy to reduce reperfusion injuries in patients during acute coronary syndromes.
\end{abstract}

(c) 2009 Elsevier Ltd. All rights reserved.

\section{Introduction}

Myocardial ischemia is the leading cause of worldwide morbidity and mortality. Early restoration of blood flow limits myocardial damage and improves survival after sustained ischemia. However, reperfusion itself can cause myocardial injuries leading to arrhythmia and contractile dysfunction [1]. Multiple mechanisms are responsible for reperfusion injuries, including massive release of reactive oxygen species (ROS), endothelial dysfunction, complement activation and leukocyte infiltration $[2,3]$. Inflammatory processes including leukocyte recruitment play a major role in the extension of myocardial damages after ischemia and reperfusion [4]. Rapidly after the restoration of blood flow, leukocytes infiltrate the myocardium in

\footnotetext{
* Corresponding author. Tel.: +41 22 3827234; fax: +41 223827245

E-mail address: Francois.Mach@unige.ch (F. Mach).

1 These authors contributed equally to this work.
}

response to complement activation and massive release of ROS [5,6]. Neutrophils, monocytes and lymphocytes are the principal immune cells implicated in this process [7-9]. Once recruited into the tissue, inflammatory cells release proteolytic enzymes and ROS that contribute to the development of injury [3]. Thus, targeting cellular recruitment at the onset of reperfusion could represent a new therapeutic strategy to reduce reperfusion injuries.

Chemokines are small chemotactic cytokines that enhance and direct leukocyte recruitment to inflammatory sites. This process is mediated through interactions of chemokines with high affinity cell surface receptors and low affinity interaction with glycosaminoglycans (GAGs) of the extracellular matrix and endothelial cell surfaces, to induce firm adhesion and trigger trans-endothelial migration [10]. Interaction of chemokines with GAGs seems to be essential for their functionality, enables localized gradients to form at inflammatory sites and facilitates chemokine retention on cell surfaces [11]. CCL5/RANTES (regulated on activated normal T-cell expressed and secreted) is secreted by several 
cell types such as endothelial cells, smooth muscle cells, macrophages, and activated T cells and binds to chemokine receptors CCR1, CCR3 and CCR5. This chemokine is implicated in migration of T cells, monocytes, basophils, eosinophils, neutrophils, natural killer and dendritic cells. In human, circulating levels of CCL5/RANTES are transiently raised during episodes of unstable angina pectoris and CCL5/RANTES peak levels appear predictive of refractory symptoms [12]. Moreover, it has been shown that both CCL5/RANTES receptors CCR 1 and CCR5 are implicated in the recruitment of neutrophils within post-ischemic tissue in animal model [13].

$\left[{ }^{44}\right.$ AANA $\left.^{47}\right]$-RANTES is a variant of CCL5/RANTES with a specific mutation in the principal RANTES/GAG binding site and has been shown to exhibit potent anti-inflammatory effects in murine models of inflammatory diseases $[14,15]$. These effects were attributed to impaired chemokine oligomerization on the endothelial cell surface that is crucial for its in vivo function, whereas receptor activation was not abrogated.

In this study, we hypothesized that the chemokine antagonist $\left[{ }^{44} \mathrm{AANA}^{47}\right]$-RANTES, interfering with leukocyte recruitment, would reduce myocardial reperfusion damages in Apolipoprotein E (ApoE) knockout mice.

\section{Materials and methods}

\subsection{Animals}

As a model of atherosclerosis, 18-22-week old apolipoprotein E $\left(\mathrm{ApoE}^{-/-}\right)$deficient mice were submitted to 10 weeks high cholesterol diet (HCD) (20.1\% fat, 1.25\% cholesterol No. D12108, Research Diets) or were maintained on standard chow diet (ND). A second group of $\mathrm{ApoE}^{-/-}$and $\mathrm{ApoE}^{-/-} \mathrm{Ccr}^{-/-}$mice was used, fed only with $\mathrm{ND}$. ApoE ${ }^{-1-} \mathrm{Ccr}^{-1-}$ double knockout mice were provided by $\mathrm{Dr}$ Christian Weber (Aachen) and both $\mathrm{ApoE}^{-/-}$and $\mathrm{ApoE}^{-/-} \mathrm{Ccr5}^{-/-}$mice were in a $\mathrm{C} 57 \mathrm{BL} / 6 \mathrm{~J}$ background [16]. All mice $\left(\mathrm{ApoE}^{-/-}\right.$and $\mathrm{ApoE}^{-/-} \mathrm{Ccr}^{-/-}$) were healthy without signs of disease during the study and all experiments were approved by local authorities.

\subsection{Treatment}

The CCL5/RANTES antagonist $\left[{ }^{44}\right.$ AANA $\left.{ }^{47}\right]$-RANTES was obtained from Merck/Serono and was administered in a single dose of $10 \mu \mathrm{g}$ i. p., 5 min before reperfusion. In parallel, control mice received sterile PBS. Sham-operated animals were submitted to the same surgical protocol than the other groups but without coronary occlusion.

\subsection{Atherosclerotic lesion size}

To determine the effect of $\mathrm{HCD}$ in $\mathrm{ApoE}^{-/-}$mice, we measured lipid levels in the serum with the Infinity kit (Thermo Electron Corporation) according to the manufacturer's guidelines. The extent of atherosclerosis was also assessed within thoracoabdominal aortas by staining for lipid deposition with oil-red-O (computerized image analysis, MetaMorph v6.0, Universal Imaging Corporation), as previously described [15].

\subsection{In vivo ischemia-reperfusion protocol}

Mice were anaesthetized with $4 \%$ isoflurane and intubated. Mechanical ventilation was performed ( $150 \mu \mathrm{l}, 120$ breaths/min) using a rodent respirator (model 683; Harvard Apparatus). Anaesthesia was maintained with $2 \%$ isoflurane delivered in $100 \% \mathrm{O}_{2}$ through the ventilator. A thoracotomy was performed and the pericardial sac was then removed. An 8-0 prolene suture was passed under the left anterior descending ( $L A D$ ) coronary artery at the inferior edge of the left atrium and tied with a slipknot to produce occlusion. A small piece of polyethylene tubing was used to secure the ligature without damaging the artery. Ischemia was confirmed by the visualization of blanching myocardium, downstream of the ligation. After 30 min ischemia, LAD coronary artery occlusion was released and reperfusion occurred. Reperfusion was confirmed by visible restoration of color to the ischemic tissue. The chest was then closed and air was evacuated from the chest cavity. The ventilator was then removed and normal respiration was restored. Animals were sacrificed after different times of reperfusion for analyses. After $24 \mathrm{~h}$ of reperfusion, to evaluate the infarct size and the area at risk, mice were re-anaesthetized with $10 \mathrm{ml} /$ $\mathrm{kg}$ ketamine-xylazine ( $12 \mathrm{mg} / \mathrm{ml}$ and $1.6 \mathrm{mg} / \mathrm{ml}$, respectively) and LAD coronary artery was re-occluded. Evan's blue dye 2\% (Sigma) was injected retro-orbitally to delineate in vivo area at risk (AAR). Hearts were rapidly excised, rinsed in $\mathrm{NaCl} 0.9 \%$, frozen and sectioned into 2$\mathrm{mm}$ transverse sections from apex to base (5-6 slices/heart). To distinguish viable (AAR) from necrotic tissue (infarction, I), slices were incubated at $37{ }^{\circ} \mathrm{C}$ with $1 \%$ triphenyltetrazolium chloride (TTC) in phosphate buffer ( $\mathrm{pH}$ 7.4) for $15 \mathrm{~min}$, fixed in $10 \%$ formaldehyde solution and photographed with a digital camera (Nikon Coolpix). The viable myocardium was visualized in red, whereas necrotic tissue appeared in white. The different zones were determined using a computerized planimetric technique (MetaMorph v6.0, Universal Imaging Corporation) and infarct size was expressed in percentage of area at risk (I/AAR).

\subsection{Ex vivo ischemia-reperfusion protocol}

We used the technique of Langendorff isolated buffer-perfused mouse heart preparation that has been previously described [17]. Briefly, mice were anaesthetized by intraperitoneal injection of sodium pentobarbital $(60 \mathrm{mg} / \mathrm{kg})$. The heart was rapidly excised and placed in ice-cold Krebs-Henseleit bicarbonate (KHB) buffer consisting of (in mmol/L): $118.5 \mathrm{NaCl}, 25 \mathrm{NaHCO}_{3}, 4.7 \mathrm{KCl}, 1.2 \mathrm{MgSO}_{4}$, $1.2 \mathrm{KH}_{2} \mathrm{PO}_{4}, 2.5 \mathrm{CaCl}_{2}$, glucose 5 and equilibrated with $95 \% \mathrm{O}_{2} / 5 \% \mathrm{CO}_{2}$ ( $\mathrm{pH}$ 7.4). Following removal of extraneous tissues (pericardium, lung, trachea, etc), the aorta was cannulated with an $18-G$ plastic cannula (1.5 cm length; $0.95 \mathrm{~mm}$, inner diameter) for a Langendorff retrograde perfusion. After stabilization, local ischemia was induced by LAD coronary artery occlusion. This procedure was performed as described in the in vivo ischemia-reperfusion protocol. After $30 \mathrm{~min}$ ischemia, reperfusion was allowed for $2 \mathrm{~h}$ by removing polyethylene tube. $\left[{ }^{44}\right.$ AANA $\left.{ }^{47}\right]$-RANTES $(1 \mu \mathrm{g} / \mathrm{ml})$ or vehicle was added within the circulating Langendorff system 5 min before the reperfusion. The concentration of antagonist used in perfused isolated hearts corresponds to the highest level detected in mouse after $\left[{ }^{44} \mathrm{AANA}^{47}\right]$ RANTES intraperitoneal injection [14]. After the reperfusion period, the suture was re-occluded and Evan's blue dye 2\% (Sigma) was injected within the heart through the cannulated aorta to delineate in vivo AAR. The TTC staining was performed as described before in the in vivo ischemia-reperfusion protocol section.

\subsection{Circulating cardiac troponin I quantification}

As circulating cardiac Troponin I (cTnI) levels have been shown to be a sensitive and specific biomarker of cardiac injury [18], we measured cTnI as a control for myocardial infarct severity. Briefly, we used a high sensitive enzyme linked immunosorbent assay (ELISA) kit (Life Diagnostics, Inc., West Chester, PA) to measure sera samples obtained from mice fed with standard chow diet and submitted to $30 \mathrm{~min}$ ischemia and $24 \mathrm{~h}$ reperfusion.

\subsection{Histological analysis}

Hearts isolated from animals were perfused with $\mathrm{NaCl} 0.9 \%$ to remove blood and were frozen in OCT. They were then cut serially from the occlusion locus to the apex in $7 \mu \mathrm{m}$ sections. 


\subsubsection{Myocardial CCL5/RANTES expression}

Myocardial CCL5/RANTES expression was detected after 5, 30 and 60 min of reperfusion, by immunostaining using a rat anti-mouse CCL5/RANTES monoclonal antibody (MAB478; R\&D). For each heart, the positive area was quantified in 3 fields of 5 independent tissue sections.

\subsubsection{Inflammatory cell recruitment}

Leukocyte recruitment within ischemic myocardium was analyzed either after $30 \mathrm{~min}$ and $24 \mathrm{~h}$ of reperfusion by immunostaining. Neutrophils, MOMA- $2^{+}$monocyte/macrophages and $\mathrm{CD}^{+} 8^{+}$macrophages were stained respectively with a rat anti-mouse neutrophils (MCA771G; Serotec), a rat anti-mouse MOMA-2 (MCA519G; Serotec) and a rat anti-mouse CD68 (MCA1957GA; Serotec) antibody. For each heart, the number of cells was counted using MetaMorph v6.0 (Universal Imaging Corporation) in 10 fields of 5 independent tissue sections. Immunostaining was performed on cryosections as previously described [19].

\subsubsection{Oxidative stress measurement}

Oxidative stress was assessed in myocardium at an early time point of reperfusion $(1 \mathrm{~h})$, since it is well known that ROS are rapidly produced at the onset of reperfusion.

We first used the superoxide-sensitive dye dihydroethidium (DHE, Molecular Probes). ROS oxidized rapidly the DHE to fluorescent ethidium, which is then intercalated into DNA. Fluorescent ethidium is therefore a presumptive marker of oxidative stress. Hearts of control or treated mice were washed in cold saline and embedded in OCT for cryosectioning. Frozen sections $(7 \mu \mathrm{m})$ of the myocardium were stained with $10 \mu \mathrm{M}$ DHE at $37^{\circ} \mathrm{C}$ for $30 \mathrm{~min}$ in a light-protected and humidified chamber. In situ fluorescence was assessed using fluorescence microscopy. The quantification of fluorescence was performed using MetaMorph v6.0 (Universal Imaging Corporation) on 3 fields per section and 5 sections per animal.

Neutrophil, monocyte and eosinophil activation is known to catalyse the formation of hypochlorous acid that reacts with proteins and induces tyrosine halogenation such as 3,5-dibromotyrosine [20]. Therefore, to assess leukocyte-derived oxidative stress, we also performed immunostaining for 3,5-dibromotyrosine using a mouse anti-dibromotyrosine monoclonal antibody (NNSMBY-020P-EX; Cosmo Bio Co., LTD). Quantification of stained area was performed by computer analysis using MetaMorph v6.0
(Universal Imaging Corporation) in 3 fields of 5 independent tissue sections.

\subsubsection{Apoptotic cell measurement}

As ROS is known to mediate apoptosis in reperfused myocardium [21], we also evaluated apoptosis after $1 \mathrm{~h}$ of reperfusion. We performed staining of frozen sections with the Dead End ${ }^{\mathrm{TM}}$ colorimetric terminal deoxinucleotidyltransferase-mediated dUTP nick end labelling (TUNEL) system (Promega) using diaminobenzidine as the chromogenic substrate (according to the manufacturer's instructions). Apoptotic index was expressed as the number of TUNELpositive cells/field.

\subsection{Circulating leukocyte quantification}

To confirm early leukocyte recruitment into inflammatory tissues, we performed leukocyte count in total blood samples after 5, 30 and 60 min of reperfusion. Blood was collected by cardiac puncture during animal sacrifice. $25 \mu \mathrm{l}$ of PBS-EDTA $5 \%$ was added to $200 \mu \mathrm{l}$ of blood and cells were measured with a hematocytometer (Sysmex KX-21N).

\subsection{Quantification of gene expression by real-time quantitative RT-PCR}

Twenty-four hours after reperfusion period, hearts were excised and total mRNA was isolated with Tri-reagent (MRC, Inc). Reverse transcription was performed using the Quantitect kit (Qiagen) according to the manufacturer's instructions. Real-time quantitative reverse transcription polymerase chain reaction (RT-PCR) (ABI Prism 7000 Sequence Detection system, Applied Biosystems) was used to determine the mRNA expression of $\mathrm{Ccl} 2 / \mathrm{Mcp}-1$ and $\mathrm{Ccl} 3$ / Mip- $1 \alpha$ as previously described [22]. Each sample was analyzed in triplicate and normalized in multiplex reaction with the use of HPRT control (TaqMan Reagent, Applied Biosystems; VIC labelled). Data were analyzed using ABI Prism software, and fold induction of mRNA levels was calculated by the comparative $C_{t}$ method (Applied Biosystems).

\subsection{Serum cytokine measurement}

Twenty-four hours after reperfusion, sera of sham, PBS- or $\left[{ }^{44} \mathrm{AANA}^{47}\right]$-RANTES-treated mice were collected. To assess systemic concentration of CCL2/MCP-1 and CCL3/MIP- $1 \alpha$, we performed ELISA
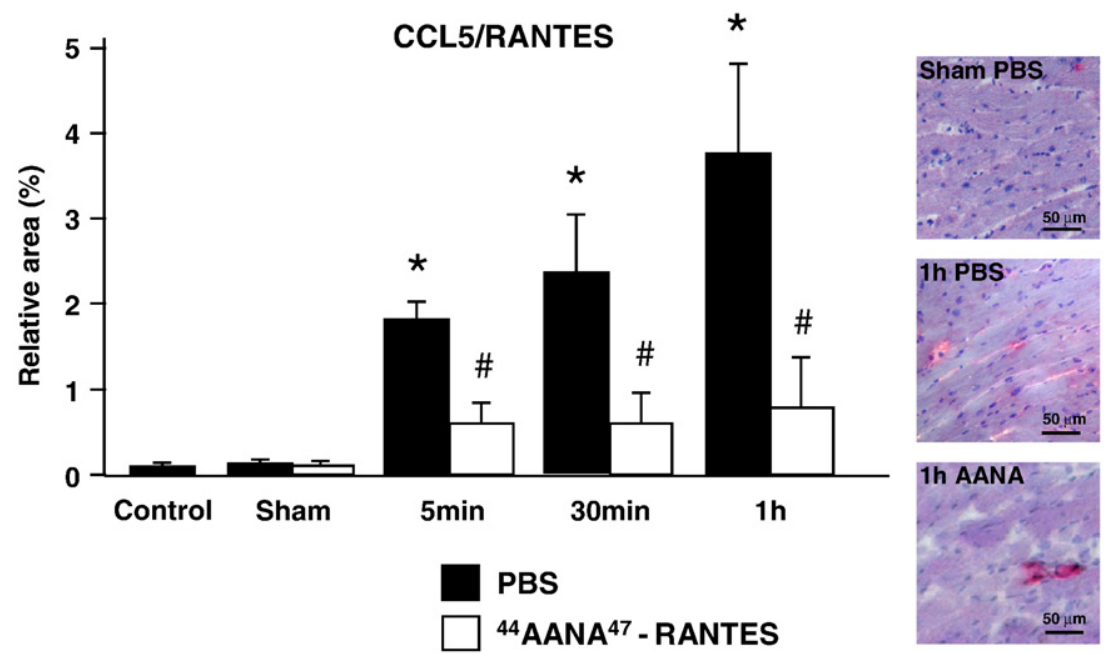

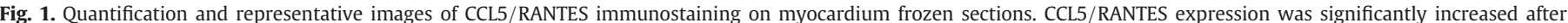

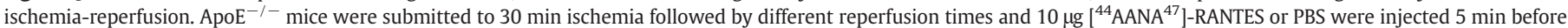

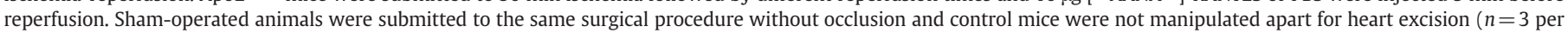
group). ${ }^{*} P<0.05$ versus Sham-operated animals. $\# P<0.05$ versus $\mathrm{PBS}$-injected mice. 
Table 1

Characteristics of different groups.

\begin{tabular}{|c|c|c|c|c|c|c|c|c|c|c|}
\hline Genetic background & $\mathrm{ApoE}^{-1-}$ & $\mathrm{ApoE}^{-1-}$ & $\mathrm{ApoE}^{-1-}$ & $\mathrm{ApoE}^{-1-}$ & $\mathrm{ApoE}^{-1-}$ & $\mathrm{ApoE}^{-1-}$ & $\mathrm{ApoE}^{-1-}$ & $\mathrm{ApoE}^{-1-} \mathrm{Ccr}^{-1-}$ & $\mathrm{ApoE}^{-1-} \mathrm{Ccr}^{-1-}$ & $\mathrm{ApoE}^{-1-} \mathrm{Ccr}^{-1-}$ \\
\hline Diet & ND & ND & ND & $\mathrm{HCD}$ & HCD & $\mathrm{HCD}$ & ND & ND & ND & ND \\
\hline Treatment & Sham & PBS & {$\left[{ }^{44} \mathrm{AANA}^{47}\right]$} & Sham & PBS & {$\left[{ }^{44} \mathrm{AANA}^{47}\right]$} & - & - & PBS & {$\left[{ }^{44} \mathrm{AANA}^{47}\right]$} \\
\hline Body weight [g] & $28.3 \pm 0.7$ & $29.6 \pm 0.8$ & $28.8 \pm 0.6$ & $30.2 \pm 0.8$ & $31.1 \pm 0.9$ & $31.3 \pm 0.7$ & $28.4 \pm 0.9$ & $30.5 \pm 0.8$ & $27.8 \pm 0.5$ & $27.9 \pm 0.4$ \\
\hline Cholesterol [mg dl ${ }^{-1}$ ] & $867 \pm 97$ & $733 \pm 72$ & $671 \pm 96$ & $1386 \pm 21^{*}$ & $1526 \pm 56^{*}$ & $1605 \pm 78^{*}$ & - & - & - & - \\
\hline $\begin{array}{l}\text { Plaque size } \\
\text { [\% of aorta surface] }\end{array}$ & $3.2 \pm 0.2$ & $3.4 \pm 0.3$ & $3.5 \pm 0.3$ & $11.6 \pm 1.1^{*}$ & $11.5 \pm 1.3^{*}$ & $11.7 \pm 1.4^{*}$ & - & - & - & - \\
\hline
\end{tabular}

ND: Standard chow diet, HCD: high cholesterol diet.

${ }^{*} P<0.05$ versus mice on normal diet.

using mouse CCL2/JE/MCP-1 and CCL3/MIP-1 $\alpha$ DuoSet (R\&D), according to the manufacturer's guidelines.

\subsection{ApoE $E^{-/-} \mathrm{Ccr}^{-/-}$double knockout mice analysis}

Ischemia-reperfusion protocols, as well as anti-CCL5/RANTES treatment were performed as described above. As for $\mathrm{ApoE}^{-1-}$ mice, infarct size was determined after $24 \mathrm{~h}$ reperfusion. We also investigated chemokines and chemokine receptors mRNA profile of these mice before and $6 \mathrm{~h}$ after reperfusion in blood. Blood was collected retro-orbitally and analyzed by real-time quantitative RTPCR for chemokines (Ccl2/Mcp-1, Ccl3/Mip-1 $\alpha$, Ccl4/Mip-1 $\beta$, and Ccl5/Rantes) and chemokine receptors (Ccr1, Ccr2, Ccr5, and Cxcr3), as previously described [22].

\subsection{Statistical analysis}

Statistical analysis was performed with Sigmastat software. Data are expressed as mean \pm SEM. Paired groups were compared using either $t$-test or non-parametric Mann-Whitney $U$ test. Multiple groups were compared using one way ANOVA (troponin I, immunostainings) or two way ANOVA (infarct size, CD68 and neutrophil immunostainings, blood expression of chemokines), followed by post-hoc Bonferroni $t$-tests. $P$ values $<0.05$ were considered significant.

\section{Results}

3.1. CCL5/RANTES is expressed in myocardium after ischemia-reperfusion

As shown in Fig. 1, our ischemia-reperfusion protocol induced CCL5/RANTES expression within mouse myocardium. While CCL5/ RANTES was detectable in weak quantities in the myocardium of 20week old $\mathrm{ApoE}^{-1-}$ mice that were not submitted to surgical procedure or only to sham-surgery, CCL5/RANTES expression increased significantly after $30 \mathrm{~min}$ ischemia followed by 5,30 or $60 \mathrm{~min}$ of reperfusion. However, when $\left[{ }^{44} A A N A^{47}\right]$-RANTES treatment was administered to animals $5 \mathrm{~min}$ before the end of ischemia, we significantly detected less CCL5/RANTES within the myocardium compared to untreated group.

\subsection{Treatment with $\left[{ }^{44} A A N A^{47}\right]$-RANTES reduces infarct size}

The effect of $\left[{ }^{44}\right.$ AANA $\left.{ }^{47}\right]$-RANTES treatment on myocardial reperfusion injury in 20-22-week old male mice $A \mathrm{poE}^{-/-}$fed with
A

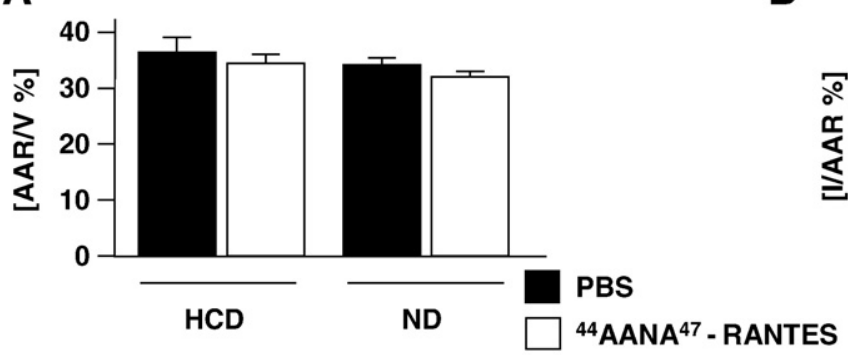

C
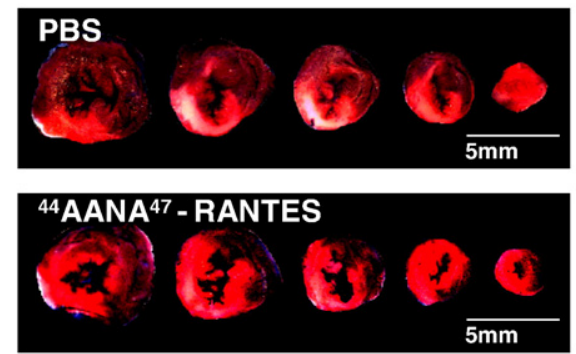

B

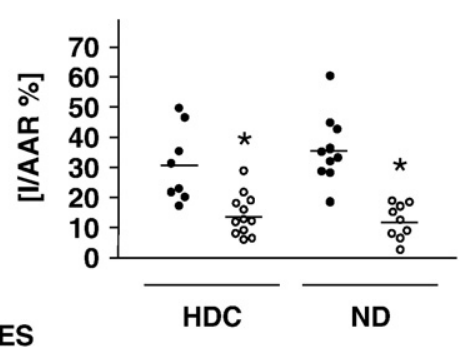

D

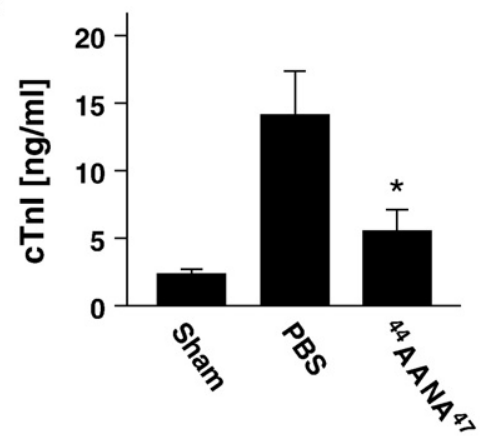

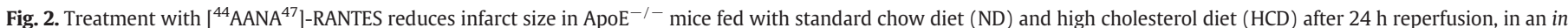

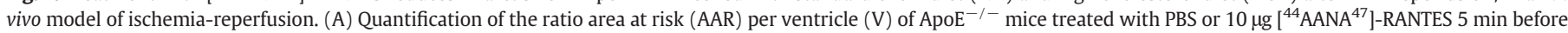

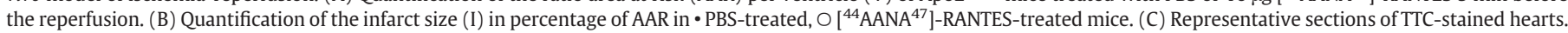
(D) Quantification of cardiac Troponin I levels after 24 h reperfusion ( $n=6$ to 7 per group). ${ }^{*} P<0.05$ versus PBS-injected mice. 
standard chow diet (ND) or high cholesterol diet (HCD) for 10 weeks was evaluated. HCD increased serum cholesterol levels as well as atherosclerotic lesions (Table 1). Oil-Red-O staining on abdominal aortas revealed $11.8 \%$ lesion per total surface in mice fed with HCD versus $3.4 \%$ for mice under ND. Severity of the ischemic insult was similar in the different groups, as shown by similar ratio of area at risk (AAR) relative to ventricle area $(\mathrm{V})$ (Fig. $2 \mathrm{~A}$ ). In mice treated with $\left[{ }^{44} \mathrm{AANA}^{47}\right]$-RANTES, we observed a significant reduction in myocardial infarct size (I/AAR) compared to PBS-treated mice. The significant decrease of necrotic tissue was similar in animals under HCD and ND (Fig. 2B). Fig. 2C illustrates representative heart slices from $\left[{ }^{44} \mathrm{AANA}^{47}\right]$-RANTES-treated and PBS-treated mice on ND. Since we did not observe any significant differences in cardioprotection between HCD-fed mice with advanced atherosclerotic lesions and ND-fed mice with few plaques, all further experiments were performed on animals fed with ND.
As a complementary readout for myocardial infarction severity, we also evaluated cardiac Troponin I (cTnI) levels within the serum. As shown in Fig. 2D, animals submitted to myocardial ischemiareperfusion protocol presented elevated serum levels of cTnI as compared to sham-operated animals. Similar to the reduction in infarct size, cTnI levels were lower in the serum of $\left[{ }^{44} \mathrm{AANA}^{47}\right]$ RANTES-treated animals than in PBS-treated mice.

\subsection{Treatment with $\left[{ }^{44} A A N A^{47}\right]$-RANTES reduces leukocyte infiltration at reperfusion}

The chemoattraction and subsequent migration of inflammatory cells within the myocardium contribute to reperfusion injury. Thus, in regard with the results described above, we investigated whether inhibition of CCL5/RANTES influences this inflammatory process through a modulation of leukocyte infiltration within reperfused
A
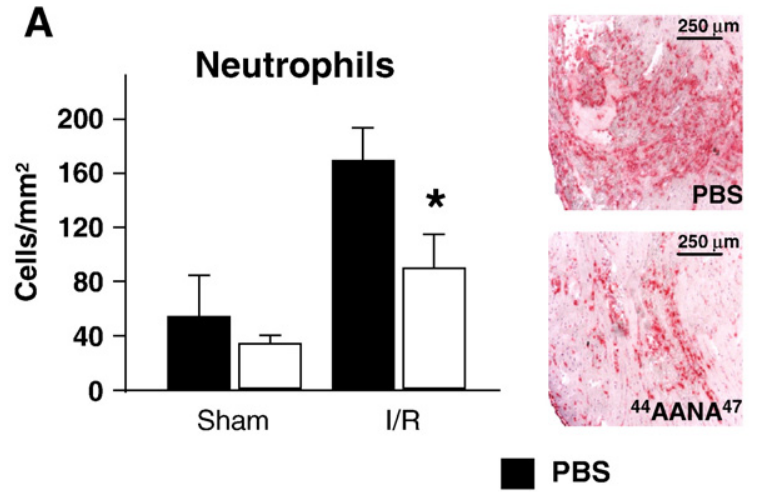

${ }^{44}$ AANA ${ }^{47}$ - RANTES
B

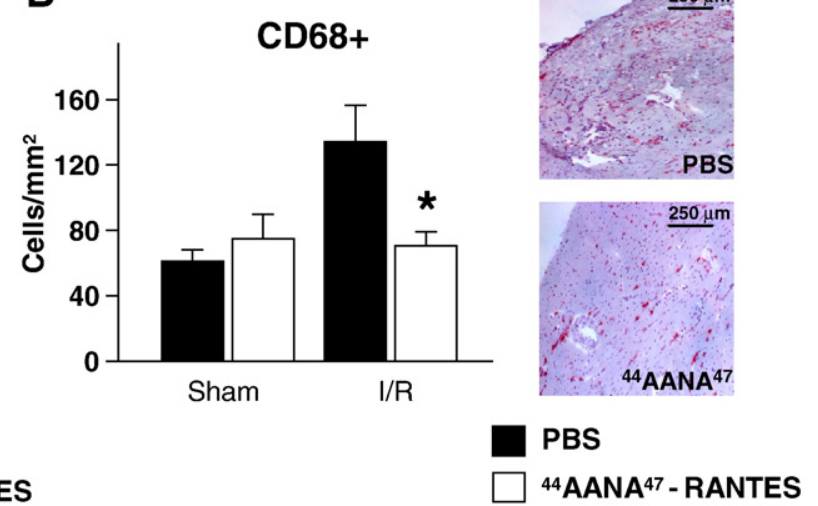

C

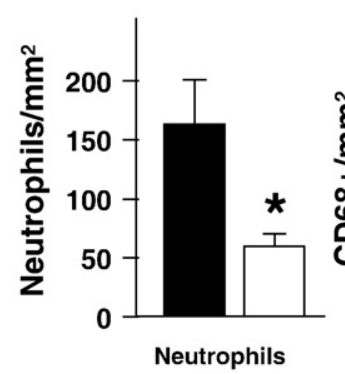

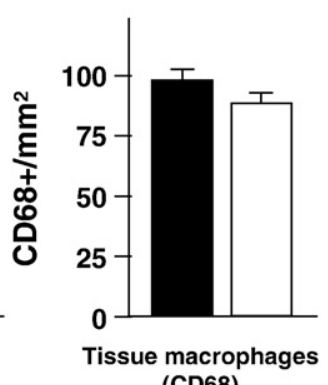

(CD68)

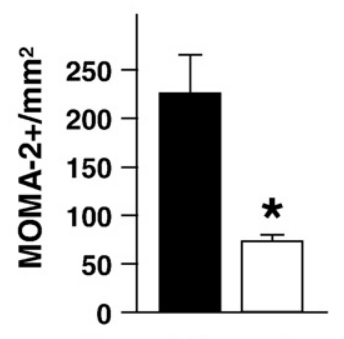

Monocyte/macrophages

(MOMA-2)

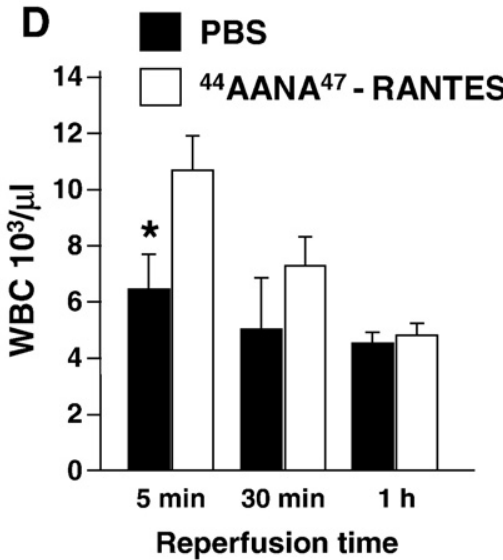

E

Ex vivo heart perfusion

AAR/V

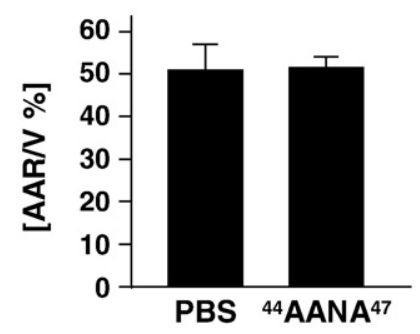

I/AAR

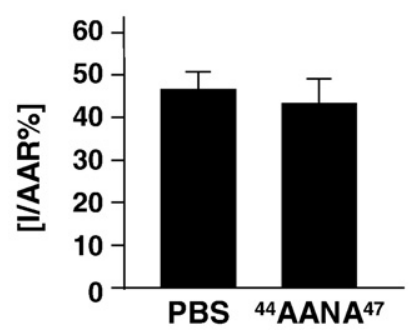

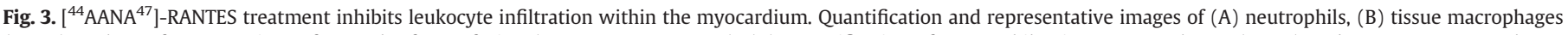

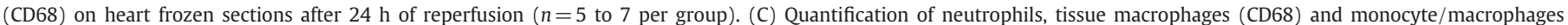

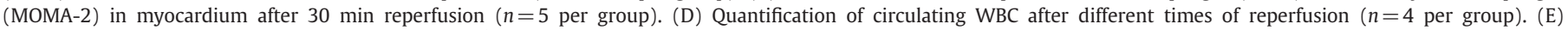

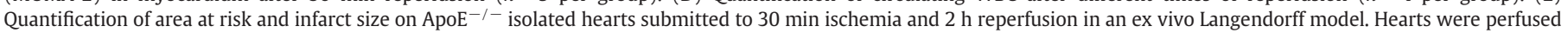
$5 \mathrm{~min}$ before and during all the reperfusion with a buffer containing $1 \mu \mathrm{g} / \mathrm{ml}\left[{ }^{44} \mathrm{AANA}{ }^{47}\right]$-RANTES or vehicle. $(n=4$ per group) $* P<0.05$ versus PBS-injected controls. 
A
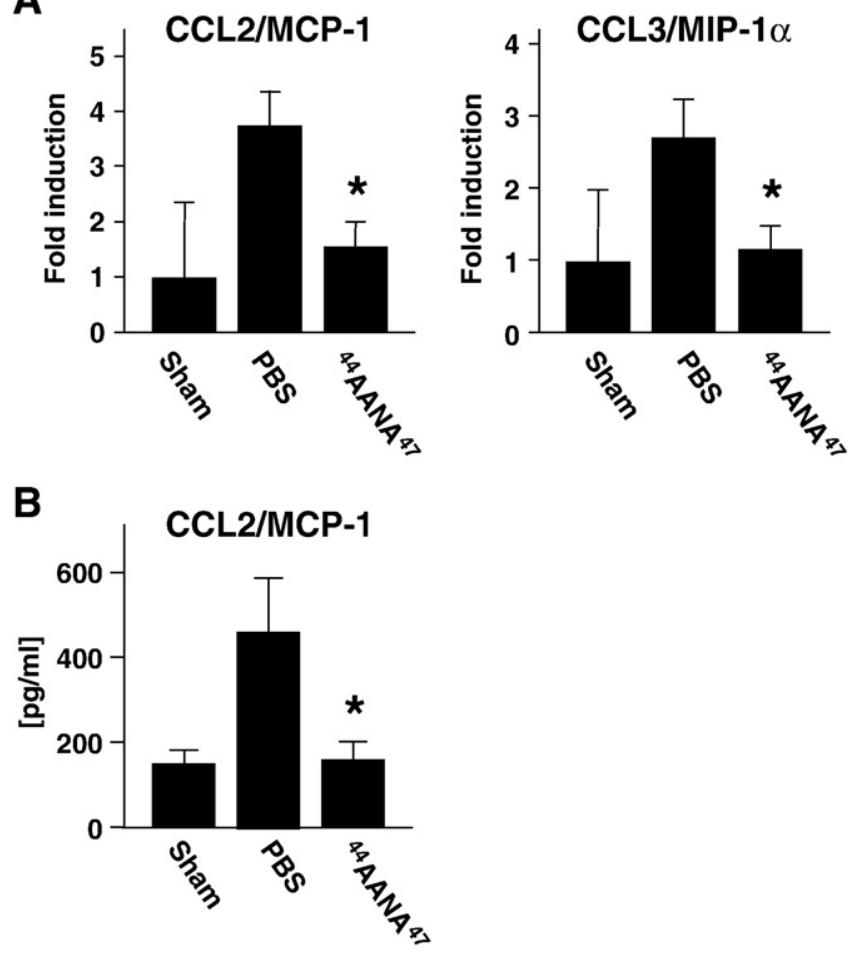

Fig. 4. $\left[{ }^{44} \mathrm{AANA}{ }^{47}\right]$-RANTES treatment reduces expression of chemokines $\mathrm{Ccl} 2 / \mathrm{Mcp}-1$ and $\mathrm{Ccl} 3 / \mathrm{Mip}-1 \alpha$. (A) Myocardial mRNA expression of chemokines $\mathrm{Ccl} 2 / \mathrm{Mcp}-1$ and $\mathrm{Ccl} 3 / \mathrm{Mip}-1 \alpha$ measured by real-time PCR after $24 \mathrm{~h}$ reperfusion ( $n=6$ to 7 per group). (B) Serum concentrations of CCL2/MCP-1 quantified by ELISA after 24 h reperfusion ( $n=6$ to 7 per group). $* P<0.05$ versus PBS-injected controls.

myocardium. Immunohistochemical analysis showed massive infiltrations of both neutrophils (Fig. 3A) and macrophages (Fig. 3B) within ischemic myocardium, $24 \mathrm{~h}$ after the onset of reperfusion. Administration of $\left[{ }^{44}\right.$ AANA $\left.{ }^{47}\right]$-RANTES significantly decreased leukocyte recruitment within the injured myocardium, whereas we did not observe any significant effect of the treatment in sham animals (Figs. $3 \mathrm{~A}$ and $\mathrm{B}$ ). The beneficial effect of CCL5/RANTES antagonism on leukocyte infiltration began early after the restoration of blood flow, since recruitment of both neutrophils and monocytes/macrophages was reduced after only 30 min reperfusion (Fig. $3 \mathrm{C}$ ). To validate this effect of $\left[{ }^{44} A A N A^{47}\right]$-RANTES on leukocyte recruitment, we also quantified circulating leukocytes after different reperfusion times. As shown in Fig. 3D, after only 5 min reperfusion, the number of circulating leukocytes was fewer in the PBS-treated group compared to $\left[{ }^{44} \mathrm{AANA}^{47}\right]$-RANTES-treated mice. This is in accordance with inflammatory cell immunostainings and suggests that $\left[{ }^{44} A A N A^{47}\right]$ RANTES inhibits leukocyte extravasation within inflammatory damaged myocardium. Moreover, to investigate whether the beneficial effect of $\left[{ }^{44} \mathrm{AANA}^{47}\right]$-RANTES on infarct size is related to the inhibition of inflammatory cell recruitment, we used a model ischemiareperfusion on ex vivo perfused heart. $\mathrm{ApoE}^{-1-}$ mouse hearts perfused in a Langendorff system were submitted to $30 \mathrm{~min}$ ischemia followed by $2 \mathrm{~h}$ of reperfusion. $\left[{ }^{44} A A N A^{47}\right]$-RANTES $(1 \mu \mathrm{g} / \mathrm{ml})$ or vehicle was injected within the closed circulating system $5 \mathrm{~min}$ before the reperfusion. As shown by the quantification of TTC staining in Fig. 3E, treatment with $\left[{ }^{44} \mathrm{AANA}^{47}\right]$-RANTES did not influence infarct size in this ex vivo model without circulating cells.

\subsection{Treatment with $\left[{ }^{44} A A N A^{47}\right]$-RANTES reduces chemokine expression within reperfused myocardium}

The chemokines CCL2/MCP-1 and CCL3/MIP-1 $\alpha$ enhance the recruitment of macrophages and neutrophils, respectively, within the tissue. Thus, we studied the effect of $\left[{ }^{44} A A N A^{47}\right]$-RANTES treatment on myocardial expression of $\mathrm{Ccl} 2 / \mathrm{Mcp}-1$ and $\mathrm{Ccl} 3 / \mathrm{Mip}-1 \alpha$ mRNA in sham-operated and $\left[{ }^{44} \mathrm{AANA}{ }^{47}\right]$-RANTES- or PBS-treated mice submitted to ischemia-reperfusion protocol. After $24 \mathrm{~h}$ reperfusion, the expression of both chemokines was increased in PBS-treated ischemic myocardium as compared to sham-operated hearts, while $\left[{ }^{44} \mathrm{AANA}^{47}\right]$-RANTES treatment significantly inhibited the upregulation of these two chemokines (Fig. 4A). Accordingly, a similar pattern was observed for serum levels of CCL2/MCP-1 (Fig. 4B), whereas serum CCL3/MIP-1 $\alpha$ levels were undetectable (data not shown).
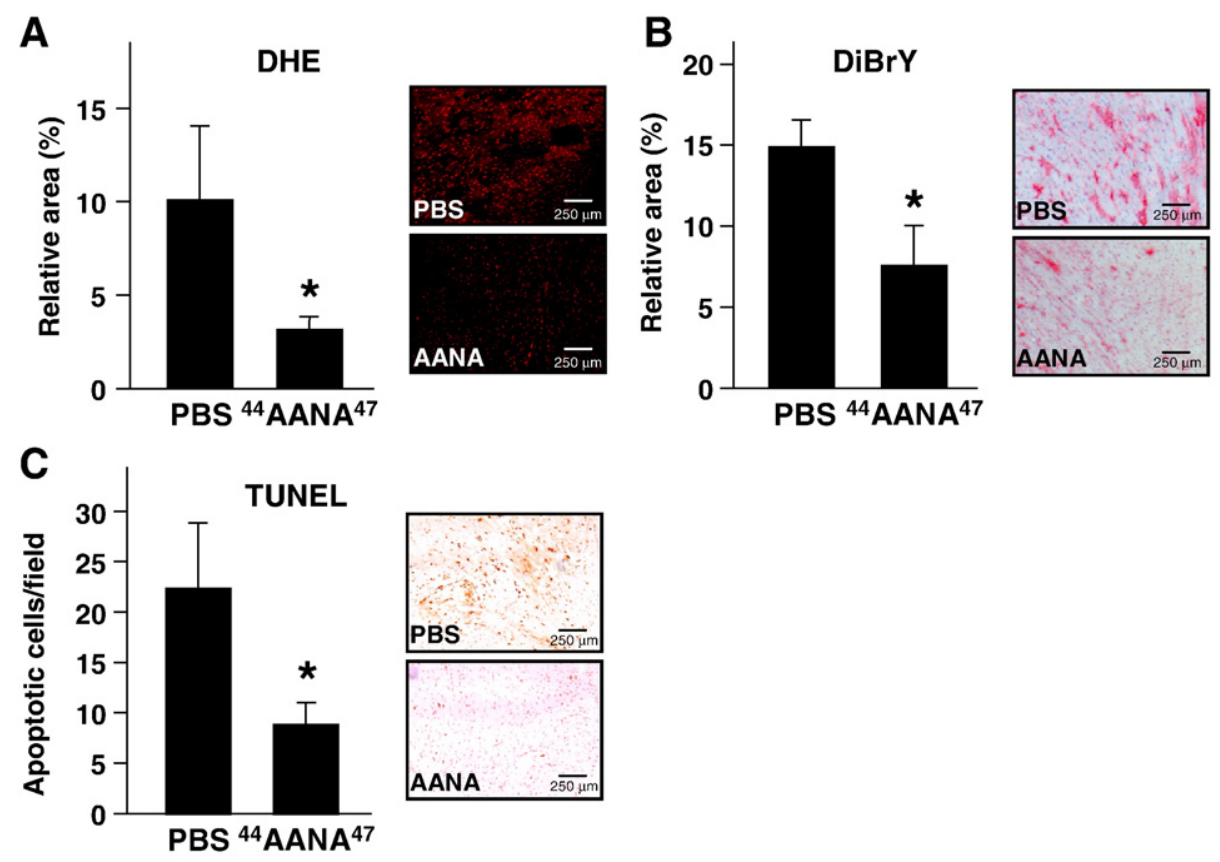

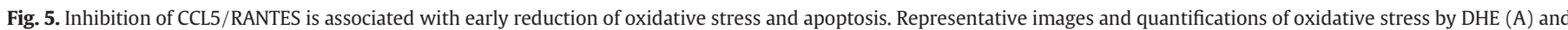
3,5-dibromothymidine (B) stainings, Apoptotic cells were quantified by TUNEL assay (C) ( $n=5$ per group). ${ }^{*} P<0.05$ versus PBS-injected controls. 
3.5. Treatment with $\left[{ }^{44} A A N A^{47}\right]$-RANTES modulates oxidative stress and apoptosis

Recruited inflammatory leukocytes are known to contribute to ROS production in reperfused myocardium [21]. Therefore, using dihydroethidium (DHE) fluorescence and 3,5-dibromotyrosine (DiBrY) quantification, we investigated oxidative stress in our model. One hour after reperfusion, the intensity of DHE staining and the surface of DiBrY stainings were lower in $\left[{ }^{44} \mathrm{AANA}{ }^{47}\right]-$ RANTES-treated mice compared to mice treated with PBS. This demonstrates that CCL5/RANTES inhibition significantly reduced myocardial oxidative stress at reperfusion (Figs. 5A and B). In addition, we also showed that $\left[{ }^{44} A A N A^{47}\right]$-RANTES treatment reduced apoptosis (Fig. 5C).
A

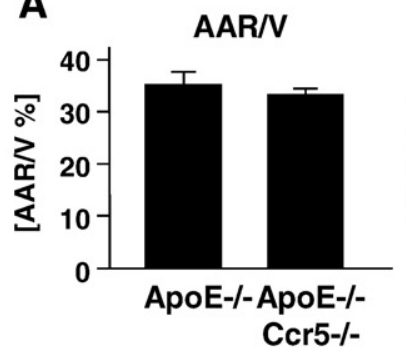

B

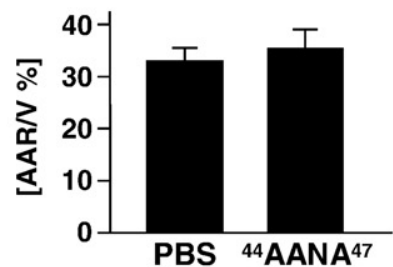

I/AAR

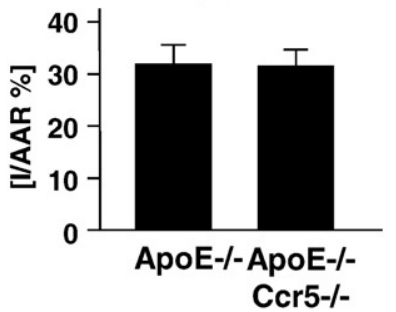

I/AAR

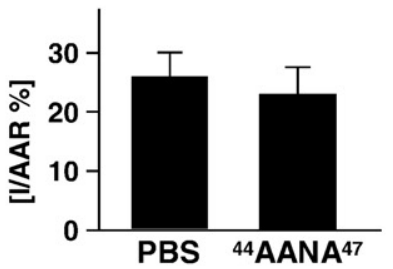

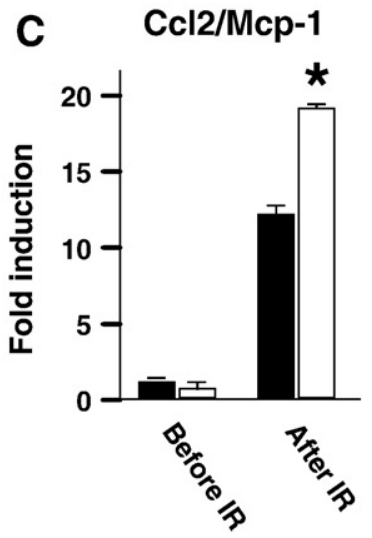

Ccr1

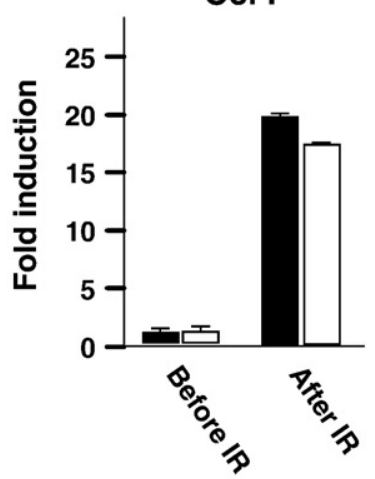

CcI3/Mip-1 $\alpha$

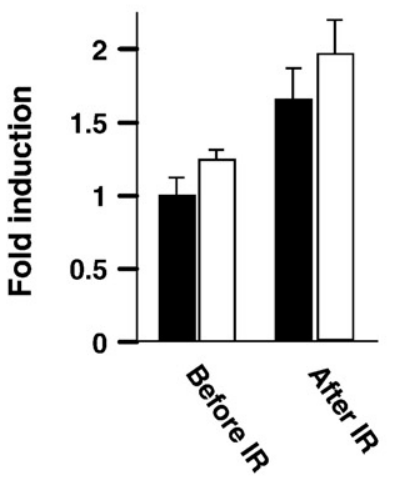

Ccr2

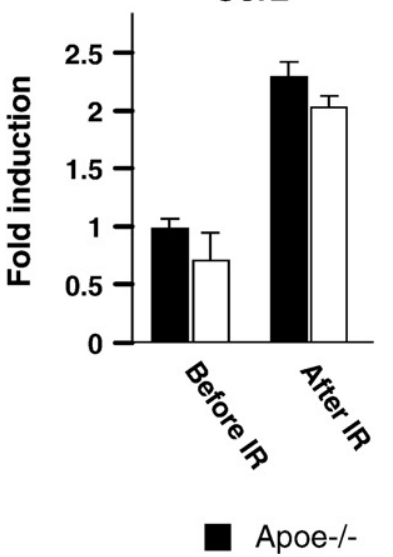

Ccl4/Mip-1 $\beta$

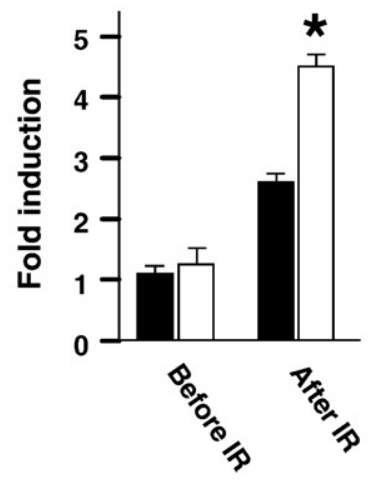

Ccr5

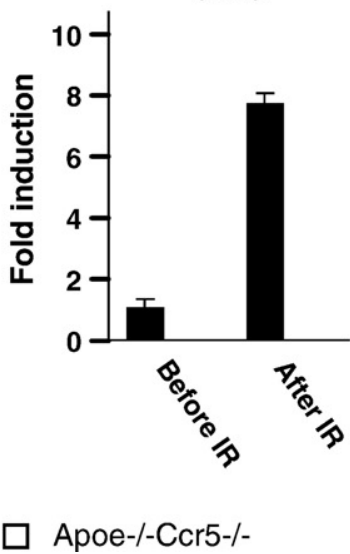

Ccl5/Rantes

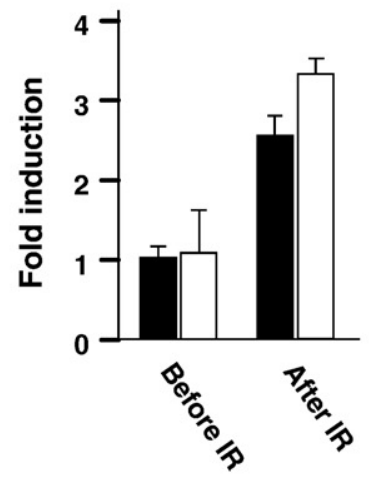

Cxcr3

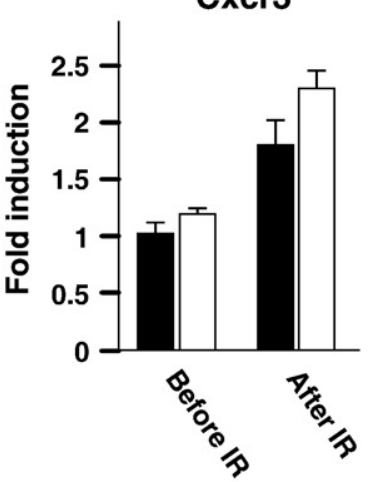

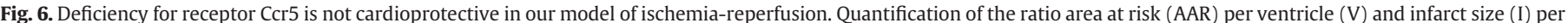

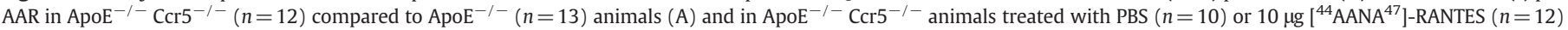

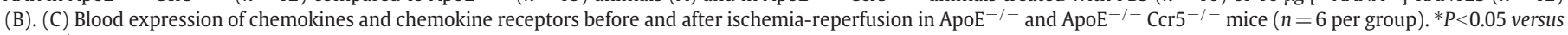
$\mathrm{ApoE}^{-/-}$control mice. 


\subsection{Effect of Ccr5 deficiency on infarct size}

To investigate in more detail the mechanism of $\left[{ }^{44} \mathrm{AANA}^{47}\right]-$ RANTES-mediated cardioprotection, we submitted mice deficient for ApoE and Ccr5 genes to our ischemia-reperfusion protocol. Surprisingly, mice deficient for both ApoE and Ccr5 were not cardioprotected (Fig. 6A). On the other hand, treatment with $\left[{ }^{44} \mathrm{AANA}^{47}\right]$-RANTES had no effect in these $A \mathrm{poE}^{-/-} \mathrm{Ccr} 5^{-1-}$ double knockout mice (Fig. 6B). Finally, we measured chemokine and chemokine receptor expression in blood both before the ischemia-reperfusion protocol and after $6 \mathrm{~h}$ reperfusion. As shown in Fig. 6C, we confirmed the lack of Ccr5 expression in the double knockout $\mathrm{ApoE}^{-1-} \mathrm{Ccr} 5^{-1-}$ mice. Furthermore, whereas basal expression of chemokines and chemokine receptors was similar between $\mathrm{ApoE}^{-1-}$ and $\mathrm{ApoE}^{-/-} \mathrm{Ccr5}^{-1-}$ mice, the expression of $\mathrm{Ccl} 2 / \mathrm{Mcp}-1$ and $\mathrm{Ccl} 4 / \mathrm{Mip} 1 \beta$ was significantly increased in the double knockout mice in comparison to $\mathrm{ApoE}^{-1-}$ animals.

\section{Discussion}

This study demonstrates that a single injection of the CCL5/ RANTES antagonist, $\left[{ }^{44}\right.$ AANA $\left.{ }^{47}\right]$-RANTES, at the onset of reperfusion reduces infarct size in atherosclerotic mice. The cardioprotective effects of $\left[{ }^{44} \mathrm{AANA}^{47}\right]$-RANTES are likely mediated through reduced i) leukocyte infiltration; ii) chemokine expression, as well as iii) oxidative stress and apoptosis in reperfused myocardium. However, deficiency for the CCL5/RANTES receptor Ccr5 exerts no beneficial effect on myocardial reperfusion injury.

In order to mimic physiological human conditions of myocardial ischemic disease and since myocardial infarction does not occur in patient without atherosclerotic plaques, we chose an atherosclerotic mouse model, the ApoE knockout mice fed either with normal or high cholesterol diet for 10 weeks. We did not observe any differences in infarct size between the different diet groups, indicating that hypercholesterolemia had no effect on this parameter, in our experimental model. Effects of hypercholesterolemia on myocardial infarction are conflicting, depending on the experimental model used. Some studies reported a beneficial effect of hypercholesterolemia on infarct size $[23,24]$, whereas others reported increased infarction in hypercholesterolemic mice $[23,25]$. These discrepancies could result from the experimental conditions as well as the duration of the high cholesterol diet. Since, in our model, high cholesterol diet did not interfere with the cardioprotection conferred by $\left[{ }^{44} A A N A^{47}\right]$-RANTES, we further used only mice fed with normal diet.

Although beneficial to limit ischemic damages, reperfusion itself can cause myocardial injury and a large body of evidence suggests a major role for inflammatory processes in the extension of tissue injuries [4]. Several studies have shown the role of complement activation [26], reactive oxygen species (ROS) [27], and the cytokine cascade [28] in the inflammatory process of myocardial infarction, and all these components could contribute to leukocyte recruitment. Neutrophils and macrophages are the principal immune cells implicated in this process [7-9,29], and, once recruited within the tissue, they further release proteases and ROS contributing to the extension of injury $[9,29]$. Thus, targeting inflammatory cell recruitment may modulate inflammatory injury during early reperfusion and lead to myocardial protection and salvage.

Inflammatory cell recruitment within reperfused myocardium is under the control of several processes, and many studies have demonstrated the role of chemokines. The implication of CCL2/MCP-1 in myocardial damages has been previously established using both Ccl2/Mcp-1 and Ccr2-deficient mice [8,30]. Tarzami et al. showed that deficiency for the Cxcr2 gene protects against myocardial infarction through a reduction of neutrophil recruitment [31]. Similarly, treatment with a blocking anti-IL-8 antibody, impairing neutrophil recruitment, reduced myocardial ischemia-reperfusion injuries [32].
CCL5/RANTES mediates the trafficking and homing of T-lymphocytes, monocytes, and other leukocytes through different chemokine receptors (CCR1, 3, and 5). CCR5 is the principal coreceptor for macrophage-tropic strains of human immunodeficiency virus, type 1 (HIV-1). It has been implicated in cardiac inflammatory disorders, arterial injury and atherosclerosis [33]. Met-RANTES, a RANTES antagonist that blocks chemokine binding to CCR1 and CCR5, has been shown to significantly reduce inflammatory responses in several animal models including rheumatoid arthritis, airways inflammation, organ transplant rejection and atherosclerosis [19]. Another CCR5 antagonist, TAK-779 known as an HIV entry inhibitor also presents anti-inflammatory properties in several models like arthritis, atherosclerosis and intestinal ischemia-reperfusion injuries [34]. Furthermore, recent clinical studies showed increased serum CCL5/RANTES levels after myocardial infarction [35,36].

In the present study, we demonstrated that the CCL5/RANTES antagonist $\left[{ }^{44} \mathrm{AANA}^{47}\right]$-RANTES reduces myocardial infarct size in atherosclerotic mice. Furthermore, we confirmed the increased expression of CCL5/RANTES in reperfused myocardium, in our animal model of ischemia-reperfusion, that was reduced by $\left[{ }^{44} A A N A^{47}\right]$ RANTES treatment. As previously mentioned, leukocyte infiltration is a crucial event in lethal reperfusion injury [7-9,29]. Thus, we hypothesized that $\left[{ }^{44} \mathrm{AANA}^{47}\right]$-RANTES treatment exerts a beneficial effect on infarct size through a limitation of leukocyte recruitment. In our experimental model, ischemia-reperfusion induced a marked infiltration of both neutrophils and macrophages within reperfused myocardium, as soon as $30 \mathrm{~min}$ after restoration of blood flow, as well as $24 \mathrm{~h}$ later. Leukocyte recruitment was characterized by an early staining of neutrophils and monocytes (MOMA-2 stainings), and a later staining of neutrophils and CD68 macrophages, within reperfused myocardium. Interestingly, $\left[{ }^{44} \mathrm{AANA}^{47}\right]$-RANTES treatment significantly reduced early infiltration of neutrophils and monocytes, as well as later recruitment of neutrophils and tissue macrophages. These data are consistent with the differentiation of infiltrated monocytes into macrophages in tissue. Furthermore, $\left[{ }^{44} \mathrm{AANA}{ }^{47}\right]$-RANTES seems to modulate cellular recruitment directly after blood restoration. Indeed, we observed that, even after 5 min of reperfusion, circulating leukocyte level was higher in the $\left[{ }^{44} \mathrm{AANA}^{47}\right]$-RANTES-treated mice compared to PBS control, suggesting a lesser recruitment level within inflammatory and reperfused tissues of treated mice. Moreover, to study the causal relationship between the reduction of infarct size and the decreased infiltration of leukocytes in response to $\left[{ }^{44} \mathrm{AANA}^{47}\right]$-RANTES treatment, we used a model of ischemia-reperfusion ex vivo, in which isolated hearts were perfused by a Krebs solution, in absence of circulating cells. Interestingly, $\left[{ }^{44} \mathrm{AANA}{ }^{47}\right]$-RANTES treatment exerted no beneficial effect on infarct size in this ex vivo perfused hearts. This strongly suggests that the decreased infarct size in response to $\left[{ }^{44} A A N A^{47}\right]-$ RANTES is mainly due to its anti-inflammatory effect on leukocyte infiltration. As discussed above, leukocyte trafficking is largely under control of chemokines [10]. Therefore, in our present study, the beneficial effect of $\left[{ }^{44} \mathrm{AANA}{ }^{47}\right]$-RANTES on leukocyte infiltration within reperfused myocardium could be explained through the reduction of CCL5/RANTES, CCL2/MCP-1 and CCL3/MIP-1 $\alpha$ myocardial expression following the ischemia-reperfusion protocol.

We further demonstrated that $\left[{ }^{44} \mathrm{AANA}^{47}\right]$-RANTES reduced ROS production within reperfused myocardium. This decrease of ROS production within the tissue could in part be attributed to the reduced number of infiltrated neutrophils. Indeed, neutrophil myeloperoxidase is known to catalyse formation of hypochlorous acid that reacts with proteins and form tyrosine halogenation such as 3,5-dibromotyrosine. Thus, these results suggest that $\left[{ }^{44} \mathrm{AANA}^{47}\right]$-RANTES reduces neutrophil-derived oxidative stress through inhibition of leukocyte infiltration into post-ischemic myocardium. Since leukocyte-induced ROS is known to contribute to tissue destruction [37] and cell apoptosis [21], reduction of ROS generation in $\left[{ }^{44} A A N A^{47}\right]$-RANTES mice could also participate to myocardial salvage. The reduced 
apoptosis rate that we observed in $\left[{ }^{44} \mathrm{AANA}{ }^{47}\right]$-RANTES-treated hearts supports this hypothesis.

In summary, we have shown that treatment with $\left[{ }^{44} \mathrm{AANA}^{47}\right]-$ RANTES modulated early post-ischemic inflammatory process, leading to fewer chemokine expression, oxidative stress and apoptosis within damaged myocardium. The impeding of this massive inflammatory process results in reduced cardiomyocytes death and diminished infarct size.

To investigate the implication of the CCL5/RANTES receptor CCR5 in our model of ischemia-reperfusion, we further used $\mathrm{ApoE}^{-/-}$and $\mathrm{ApoE}^{-1-} \mathrm{Ccr}^{-1-}$ mice. Interestingly, $\mathrm{ApoE}^{-1-} \mathrm{Ccr}^{-1-}$ mice did not show any differences in infarct size when compared to $\mathrm{ApoE}^{-1-}$ control mice. To understand this surprising result, we also treated $\mathrm{ApoE}^{-1-} \mathrm{Ccr}^{-1-}$ mice submitted to ischemia-reperfusion with $\left[{ }^{44} \mathrm{AANA}^{47}\right]$-RANTES. Indeed, we wondered whether the cardioprotective properties of $\left.{ }^{44} A A N{ }^{47}\right]$-RANTES were effective without the CCR5 receptor, possibly by reducing the interaction of CCL5/RANTES with other receptors, like CCR1. Our results showed that $\left[{ }^{44} A A N A^{47}\right]-$ RANTES treatment was ineffective in $\mathrm{ApoE}^{-1-} \mathrm{Ccr} 5^{-/-}$mice, suggesting that its beneficial effect was rather due to impairment of the interaction between CCL5/RANTES and CCR5 receptor than CCR1. One possible explanation for the lack of beneficial effect of $\left[{ }^{44} \mathrm{AANA}^{47}\right]$-RANTES in the ApoE ${ }^{-1-} \mathrm{Ccr} 5^{-1-}$ mice could reside in the enhanced $\mathrm{Ccl} 2 / \mathrm{Mcp}-1$ and $\mathrm{Ccl} 4 / \mathrm{Mip}-1 \beta$ expression in blood of double knockout mice at reperfusion, compared to $\mathrm{ApoE}^{-/-}$control mice. Indeed, since the chemokine and chemokine receptor family is very complex and redundant, our present results suggest that, in our model of ischemia-reperfusion, $\mathrm{Ccr} 5$ deficiency could be compensated by overexpression of $\mathrm{Ccl} 2 / \mathrm{Mcp}-1$ and $\mathrm{Ccl} 4 / \mathrm{Mip}-1 \beta$. In the same manner, in a model of kainic acid-induced hippocampal injury, Ccr5 deficiency has no effect on injury due to a compensatory effect by increased Ccr2 and Ccr3 mRNA expression [38].

To conclude, we have demonstrated that treatment with one bolus injection of $\left[{ }^{44} \mathrm{AANA}{ }^{47}\right]$-RANTES, 5 min before reperfusion, reduced myocardial reperfusion injuries in vivo in mice. These beneficial effects were associated with reduction of leukocyte infiltration during reperfusion, paralleled to a decrease of chemokines CCL3/MIP- $1 \alpha$ and CCL2/MCP-1 and a reduction of both oxidative stress and apoptosis. This cardioprotective effect seemed to be mediated through the inhibition of CCL5/RANTES interaction with its main receptor CCR5, since $\left[{ }^{44} \mathrm{AANA}{ }^{47}\right]$-RANTES treatment was not efficient in double ApoE Ccr5 deficient mice. Furthermore, the lack of beneficial cardioprotective effect in $\mathrm{ApoE}^{-/-} \mathrm{Ccr} 5^{-/-}$mice could result from the compensatory expression of chemokines by circulating cells that may counterbalance $\mathrm{Ccr} 5$ deficiency in reperfused mice.

Therefore, this study provides the first evidence that inhibition of CCL5/RANTES exerts cardioprotective effects, specifically during early reperfusion, through anti-inflammatory and anti-oxidant properties. Our findings indicate that blockade of chemokine receptor/ligand interactions might become a novel therapeutic strategy to reduce reperfusion myocardial injuries in patients undergoing coronary angioplasty during acute coronary syndromes.

\section{Acknowledgments}

This research is funded by EU FP7, Grant number 201668, AtheroRemo, the Swiss National Science Foundation (310030118245), the Foundation for Medical Researches (Geneva, Switzerland) to FM, the Foundation for Medical Research (France) and Agir à Dom (France) to CA.

\section{References}

[1] Kloner RA, Przyklenk K, Campbell CA. Coronary reperfusion following experimental myocardial infarction. J Card Surg 1987;2(2):291-7.

[2] Park JL, Lucchesi BR. Mechanisms of myocardial reperfusion injury. Ann Thorac Surg 1999;68(5):1905-12.
[3] Frangogiannis NG, Smith CW, Entman ML. The inflammatory response in myocardial infarction. Cardiovasc Res 2002;53(1):31-47.

[4] Entman ML, Smith CW. Postreperfusion inflammation: a model for reaction to injury in cardiovascular disease. Cardiovasc Res 1994;28(9):1301-11.

[5] Dhalla NS, Elmoselhi AB, Hata T, Makino N. Status of myocardial antioxidants in ischemia-reperfusion injury. Cardiovasc Res 2000;47(3):446-56.

[6] Birdsall HH, Green DM, Trial J, Youker KA, Burns AR, MacKay CR, et al. Complement C5a, TGF-beta 1, and MCP-1, in sequence, induce migration of monocytes into ischemic canine myocardium within the first one to five hours after reperfusion. Circulation 1997;95(3):684-92.

[7] D'Amico M, Di Filippo C, La M, Solito E, McLean PG, Flower RJ, et al. Lipocortin 1 reduces myocardial ischemia-reperfusion injury by affecting local leukocyte recruitment. FASEB J 2000;14(13):1867-9.

[8] Frangogiannis NG, Dewald O, Xia Y, Ren G, Haudek S, Leucker T, et al. Critical role of monocyte chemoattractant protein-1/CC chemokine ligand 2 in the pathogenesis of ischemic cardiomyopathy. Circulation 2007;115(5):584-92.

[9] Hansen PR. Role of neutrophils in myocardial ischemia and reperfusion. Circulation 1995;91(6):1872-85.

[10] Charo IF, Ransohoff RM. The many roles of chemokines and chemokine receptors in inflammation. N Engl J Med 2006;354(6):610-21.

[11] Proudfoot AE, Handel TM, Johnson Z, Lau EK, LiWang P, Clark-Lewis I, et al. Glycosaminoglycan binding and oligomerization are essential for the in vivo activity of certain chemokines. Proc Natl Acad Sci U S A 2003;100(4):1885-90.

[12] Kraaijeveld AO, de Jager SC, de Jager WJ, Prakken BJ, McColl SR, Haspels I, et al. CC chemokine ligand-5 (CCL5/RANTES) and CC chemokine ligand-18 (CCL18/ PARC) are specific markers of refractory unstable angina pectoris and are transiently raised during severe ischemic symptoms. Circulation 2007;116(17): 1931-41.

[13] Reichel CA, Khandoga A, Anders HJ, Schlondorff D, Luckow B, Krombach F. Chemokine receptors $\mathrm{Ccr} 1, \mathrm{Ccr} 2$, and $\mathrm{Ccr} 5$ mediate neutrophil migration to postischemic tissue. J Leukoc Biol 2006;79(1):114-22.

[14] Johnson Z, Kosco-Vilbois MH, Herren S, Cirillo R, Muzio V, Zaratin P, et al. Interference with heparin binding and oligomerization creates a novel antiinflammatory strategy targeting the chemokine system. J Immunol 2004;173(9): 5776-85.

[15] Braunersreuther V, Steffens S, Arnaud C, Pelli G, Burger F, Proudfoot A, et al. A novel RANTES antagonist prevents progression of established atherosclerotic lesions in mice. Arterioscler Thromb Vasc Biol 2008;28(6):1090-6.

[16] Braunersreuther V, Zernecke A, Arnaud C, Liehn EA, Steffens S, Shagdarsuren E, et al. Ccr5 but not $\mathrm{Ccr} 1$ deficiency reduces development of diet-induced atherosclerosis in mice. Arterioscler Thromb Vasc Biol 2007;27(2):373-9.

[17] Pellieux C, Aasum E, Larsen TS, Montessuit C, Papageorgiou I, Pedrazzini T, et al. Overexpression of angiotensinogen in the myocardium induces downregulation of the fatty acid oxidation pathway. J Mol Cell Cardiol 2006;41(3):459-66.

[18] Eckle T, Grenz A, Kohler D, Redel A, Falk M, Rolauffs B, et al. Systematic evaluation of a novel model for cardiac ischemic preconditioning in mice. Am J Physiol, Heart Circ Physiol 2006;291(5):H2533-40.

[19] Veillard NR, Kwak B, Pelli G, Mulhaupt F, James RW, Proudfoot AE, et al. Antagonism of RANTES receptors reduces atherosclerotic plaque formation in mice. Circ Res 2004:94(2):253-61.

[20] Wu W, Chen Y, d'Avignon A. Hazen SL. 3-bromotyrosine and 3,5-dibromotyrosine are major products of protein oxidation by eosinophil peroxidase: potential markers for eosinophil-dependent tissue injury in vivo. Biochemistry 1999;38 (12):3538-48.

[21] Zhao ZQ. Oxidative stress-elicited myocardial apoptosis during reperfusion. Curr Opin Pharmacol 2004;4(2):159-65.

[22] Veillard NR, Steffens S, Burger F, Pelli G, Mach F. Differential expression patterns of proinflammatory and antiinflammatory mediators during atherogenesis in mice. Arterioscler Thromb Vasc Biol 2004;24(12):2339-44.

[23] Girod WG, Jones SP, Sieber N, Aw TY, Lefer DJ. Effects of hypercholesterolemia on myocardial ischemia-reperfusion injury in LDL receptor-deficient mice. Arterioscler Thromb Vasc Biol 1999;19(11):2776-81.

[24] Jones SP, Girod WG, Marotti KR, Aw TY, Lefer DJ. Acute exposure to a high cholesterol diet attenuates myocardial ischemia-reperfusion injury in cholesteryl ester transfer protein mice. Coron Artery Dis 2001;12(1):37-44.

[25] Scalia R, Gooszen ME, Jones SP, Hoffmeyer M, Rimmer III DM, Trocha SD, et al. Simvastatin exerts both anti-inflammatory and cardioprotective effects in apolipoprotein E-deficient mice. Circulation 2001;103(21):2598-603.

[26] Kilgore KS, Friedrichs GS, Homeister JW, Lucchesi BR. The complement system in myocardial ischaemia/reperfusion injury. Cardiovasc Res 1994;28(4):437-44

[27] Lefer DJ, Granger DN. Oxidative stress and cardiac disease. Am J Med 2000;109(4): 315-23.

[28] Chandrasekar B, Freeman GL. Induction of nuclear factor kappaB and activation protein 1 in postischemic myocardium. FEBS Lett 1997;401(1):30-4.

[29] Jordan JE, Zhao ZQ, Vinten-Johansen J. The role of neutrophils in myocardial ischemia-reperfusion injury. Cardiovasc Res 1999;43(4):860-78.

[30] Hayasaki T, Kaikita K, Okuma T, Yamamoto E, Kuziel WA, Ogawa H, et al. CC chemokine receptor-2 deficiency attenuates oxidative stress and infarct size caused by myocardial ischemia-reperfusion in mice. Circ J 2006;70(3):342-51.

[31] Tarzami ST, Miao W, Mani K, Lopez L, Factor SM, Berman JW, et al. Opposing effects mediated by the chemokine receptor CXCR2 on myocardial ischemia-reperfusion injury: recruitment of potentially damaging neutrophils and direct myocardial protection. Circulation 2003;108(19):2387-92.

[32] Boyle Jr EM, Kovacich JC, Hebert CA, Canty Jr TG, Chi E, Morgan EN, et al. Inhibition of interleukin-8 blocks myocardial ischemia-reperfusion injury. J Thorac Cardiovasc Surg 1998;116(1):114-21. 
[33] Tedgui A, Mallat Z. Cytokines in atherosclerosis: pathogenic and regulatory pathways. Physiol Rev 2006;86(2):515-81.

[34] Akahori T, Sho M, Kashizuka H, Nomi T, Kanehiro H, Nakajima Y. A novel CCR5/ CXCR3 antagonist protects intestinal ischemia/reperfusion injury. Transplant Proc 2006;38(10):3366-8.

[35] Kobusiak-Prokopowicz M, Orzeszko J, Mazur G, Mysiak A, Orda A, Poreba R, et al. Chemokines and left ventricular function in patients with acute myocardial infarction. Eur J Intern Med 2007;18(4):288-94.

[36] Parissis JT, Adamopoulos S, Venetsanou KF, Mentzikof DG, Karas SM, Kremastinos
DT. Serum profiles of $\mathrm{C}-\mathrm{C}$ chemokines in acute myocardial infarction: possible implication in postinfarction left ventricular remodeling. J Interferon Cytokine Res 2002;22(2):223-9.

[37] Weiss SJ. Tissue destruction by neutrophils. N Engl J Med 1989;320(6): 365-76.

[38] Chen Z, Yu S, Bakhiet M, Winblad B, Zhu J. The chemokine receptor CCR5 is not a necessary inflammatory mediator in kainic acid-induced hippocampal injury: evidence for a compensatory effect by increased CCR2 and CCR3. J Neurochem 2003;86(1):61-8. 